University of Nebraska - Lincoln

DigitalCommons@University of Nebraska - Lincoln

2010

\title{
Locomotion in Response to Shifting Climate Zones: Not So Fast
}

Martin E. Feder

Theodore Garland Jr.

James H. Marden

Anthony J. Zera

Follow this and additional works at: https://digitalcommons.unl.edu/bioscifacpub

Part of the Biology Commons

This Article is brought to you for free and open access by the Papers in the Biological Sciences at DigitalCommons@University of Nebraska - Lincoln. It has been accepted for inclusion in Faculty Publications in the Biological Sciences by an authorized administrator of DigitalCommons@University of Nebraska - Lincoln. 


\title{
Locomotion in Response to Shifting Climate Zones: Not So Fast
}

\author{
Martin E. Feder, ${ }^{1}$ Theodore Garland, Jr., ${ }^{2}$ \\ James H. Marden, ${ }^{3}$ and Anthony J. Zera ${ }^{4, *}$
}

\author{
${ }^{1}$ Department of Organismal Biology and Anatomy, University of Chicago, Chicago, \\ Illinois 60637; email: m-feder@uchicago.edu \\ ${ }^{2}$ Department of Biology, University of California, Riverside, California 92521; \\ email: tgarland@ucr.edu \\ ${ }^{3}$ Department of Biology, Pennsylvania State University, University Park, \\ Pennsylvania 16802; email: jhm10@psu.edu \\ ${ }^{4}$ School of Biological Sciences, University of Nebraska, Lincoln, Nebraska 68588; \\ email: azera1@unlnotes.unl.edu
}

Annu. Rev. Physiol. 2010. 72:167-90

First published online as a Review in Advance on October 21, 2009

The Annual Review of Physiology is online at physiol.annualreviews.org

This article's doi:

10.1146/annurev-physiol-021909-135804

Copyright (c) 2010 by Annual Reviews. All rights reserved

0066-4278/10/0315-0167\$20.00

*All authors contributed equally.

\section{Key Words}

climate change, biological variation, evolutionary physiology, trade-off, plasticity, migration

\begin{abstract}
Although a species' locomotor capacity is suggestive of its ability to escape global climate change, such a suggestion is not necessarily straightforward. Species vary substantially in locomotor capacity, both ontogenetically and within/among populations, and much of this variation has a genetic basis. Accordingly, locomotor capacity can and does evolve rapidly, as selection experiments demonstrate. Importantly, even though this evolution of locomotor capacity may be rapid enough to escape changing climate, genetic correlations among traits (often due to pleiotropy) are such that successful or rapid dispersers are often limited in colonization or reproductive ability, which may be viewed as a tradeoff. The nuanced assessment of this variation and evolution is reviewed for well-studied models: salmon, flying versus flightless insects, rodents undergoing experimental evolution, and metapopulations of butterflies. This work reveals how integration of physiology with population biology and functional genomics can be especially informative.
\end{abstract}




\section{INTRODUCTION}

Poleward movement of terrestrial surface isotherms is expected to average between $3.8 \mathrm{~km}$ and $5.9 \mathrm{~km}$ per year if current trends of global climate change continue (1). In principle, any animal species whose members have the physiological capacity to sense and respond to temperature by moving at a comparable rate, or to track the movement of a community of codependent species by whatever mechanism, could maintain its pre-existing thermal environment and thereby mitigate the impact of changing climate. Table 2 in Alerstam et al. (2) illustrates the diversity of migration capacities. Assessing this physiological capacity, moreover, is relatively straightforward. Recent advances in the telemetry of unrestrained animals enable accurate quantitation of actual movements in nature, even of relatively small individuals $(3,4)$. Laboratory ergometers can accommodate the full range of locomotor behaviors in animals, and be used to relate locomotor capacity to its biochemical, physiological, and biomechanical substrates (5). From this knowledge, prediction of a species' capacity for comigration with shifting climatic zones should be possible. That is, in a race between shifting climatic zones and animals, which species have the physiological capacity to keep up and which do not [thereby necessitating tolerance of a novel climate $(6,7)$ or managed relocation (8)]?

The underlying logic and validity of this question seem straightforward. Indeed, dispersal capacity and susceptibility to climate change can be inversely related empirically (e.g., 9) and theoretically (10). In reality, the answer is so complex and nuanced that robust predictions of species' longevities through their comigratory capacities will be elusive $(11,12)$. A major reason for this elusiveness from the perspective of evolutionary physiology $(13,14)$ is that migratory capacity is itself highly variable, both among individuals of a species and within the lifetimes of both individuals and species. The variation, which may both exaggerate and damp capacity for successful comigration, should inform predictions of the effects of climate change.
Before taking up this theme, some qualifications are necessary. First, as recently reviewed $(6,15)$, climate change as experienced by large $(>10 \mathrm{~kg})$ terrestrial animals such as ourselves is often irrelevant to smaller terrestrial animals, for which movement from microclimate to microclimate without macrogeographical relocation may suffice to maintain a constant thermal environment. Microclimates at a given locale can be highly diverse, and movement among them can be the equivalent of poleward migration. An excellent recent example is a study of six species of small arthropods living on tree trunks (16). Through movement of typically $<1 \mathrm{~m}$ both within and among trunk microhabitats (radial crevices, vertical crevices, lichens, algal crusts, etc.), all species were able to offset the effect of seasonal climate change, even when suitable microhabitats were rare. Case studies too numerous to cite establish that individuals of most species exhibit thermoregulatory movement among microclimates. As also emphasized (16), however, these are but case studies, and systematic (e.g., community-wide) characterizations of actual compensatory microclimate use are so rare that we are prone to ascertainment bias by the well-studied cases. Clearly, (a) gross climate change can override microclimatic variation (if, for example, the host trees of the arthropods succumbed to it), and (b) not all species can or do benefit from compensatory microclimate use, but are the species that comigrate with shifting climatic zones and those that become extinct the rule or the exception? We do not know for certain. Many faunal surveys are far too coarse-grained to address this issue.

Second, even if comigration with shifting climatic zones is physiologically feasible, it is not without physiological cost (5). As the reproductive migration of anadromous salmon most famously exemplifies, migration can be so taxing of mass and energy reserves and tissue homeostasis that migrating organisms die soon afterwards (17). Diverse organs atrophy in migrating birds (18). Additional costs include time, risk of predation, and susceptibility to parasites and disease (2). These costs and risks may detract from the adaptive benefit of 
comigration, which may be beneficial nonetheless if not migrating leads to reproductive failure. Aside from physiological costs, organisms may lack the behavioral propensity to migrate when appropriate.

Third, as the ensuing and accompanying reviews elaborate, arrival of an individual animal in a zone of acceptable climate is but the first step of a multicomponent process of colonization; should any other component fail, the first step will be for naught. Other components might include, for example, suitable levels of the various abiotic variables [respiratory gases, $\mathrm{pH}$, water/humidity, etc. (7)], suitable shelter and nesting sites, resynchronization of biological timing (19), availability of prey and commensal species (each of which may be subject to the same pressures) as for the focal species), and finding a mate if other members of the same species already occur at the destination. Moreover, arrival of a single animal will usually be insufficient to establish a genetically diverse breeding population at the new site.

These obstacles aside, it would seem that species with highly developed locomotor capacities should be able to match the speed at which climatic zones shift poleward, whereas those with less-developed locomotor capacities might not. This proposition assumes, however, that locomotor capacity is uniform both within a species and over the time during which climate change might necessitate comigration. This review critically examines each of these assumptions, first by considering the physiology of within-species polymorphisms in locomotor capacity, next by examining the rate at which locomotor capacity can evolve in selection experiments, and finally by assessing population variation in locomotor capacity.

The following review may seem eclectic in that it emphasizes work on a few model systems (salmon, rodents, insects), whereas the challenge of comigration confronts numerous and diverse organisms (20). This approach enables us to explore the underlying issues in detail. The conclusions, however, ought to be applicable to motile animal species in general.

\section{INSIGHTS FROM SALMON}

Salmon have been a major model for understanding how climate affects migration and heritable variation in seasonal initiation of migration, how photoperiod and temperature interact to affect timing and endocrine control of physiological traits important for the migration, and how temperature affects locomotor physiology critical for upstream migrations to spawning sites. Here we examine some results from that body of work.

\section{Species Capable of Comigration But Reliant upon Photoperiodic Cues May Fail to Initiate Movement Appropriately}

Locomotor capacity can only affect comigration after an animal has chosen to move. Factors that cue the initiation of dispersal include photoperiod and temperature, in combination. Because the photoperiodic regime at a given site is unrelated to climate change, species reliant upon it as a migration cue may prolong their stay at a hostile site, with predictable consequences. Likewise, migratory species that rely jointly on day length and temperature to cue their phenology may remain in place despite increasingly adverse conditions. Common garden-reared juvenile Atlantic salmon (Salmo salar) from different populations differ by up to two weeks in the median date of downstream migration (21), which indicates that there is substantial heritable variation in this trait. Although the mechanistic source of the variation in juvenile migration is not clear, it is apparent that photoperiod plays a strong role.

Experiments that varied both temperature and photoperiod have shown that photoperiod had a much greater effect on the developmental trajectory of physiological variables related to migration and preparation for seawater in juvenile Atlantic salmon (22). Fish reared under a short and invariant day length (LD 9:15) and earlier warming never reached the full smolt physiological state, whereas earlier warming
LD: hours of light and dark in a day 
GH: growth hormone

with normal photoperiod accelerated maturation (although not the date of peak maturation). Thus, temperature accelerated the early course of physiological maturation required for migration but did little to shift the ultimate time of readiness for migration and did not serve as an independent cue.

How photoperiod controls adult salmon physiology and behavior is becoming increasingly well understood. Day length affects clock gene expression and rhythmicity in Atlantic salmon brains (23). Pacific populations of chinook salmon (Oncorbynchus tshawytscha) show a latitudinal cline in allele length and frequency of the two most common Clock1b alleles (24). Timing of the upstream adult migration in these populations explained $41 \%$ of the genetic variance in Clock1b length among populations, whereas migration timing explained only $13 \%$ of the variance in 13 microsatellite loci (24). In rainbow trout (O. mykiss), the clock gene maps to a quantitative trait locus that has major effects on the timing of spawning. This growing body of evidence for strong effects of photoperiodinduced physiological clocks on salmon life history provides a mixed message regarding the predicted ability of salmon to make appropriate adjustments to climate change. On the one hand, control of their phenology by physiological clocks, which are temperature compensated (25), might mean that salmon will not readily adapt to climate change. On the other hand, these studies identify genetic variation in the clock mechanism itself that shows evidence of historical and presumably ongoing adaptation to proper timing of life-history events at different temperature regimes. These data provide a glimmer of hope that acquisition of alleles from more warm-adapted salmon populations may allow more poleward populations to shift the timing of key life-history events to respond appropriately to changing climate.

\section{Pleiotropic Effects of Genes Relevant to Migration}

Growth hormone (GH) titer covaries with dispersal physiology of migrating salmon (22), and therefore variation in expression of GH may be one way that salmon could respond to climate change. $\mathrm{GH}$ is a highly pleiotropic hormone (i.e., affects many traits), however, and thereby exemplifies how climate-imposed selection might affect multiple traits. Transgenic coho salmon (O. kisutch) that express more GH show phenotypic variation in juvenile dispersal (26), reduced group cohesion (schooling), and more exploratory behavior. Most interestingly, the greatly enhanced appetite of GH transgenic fish causes striking population effects (27) that could blunt selection for elevated $\mathrm{GH}$ production in free-living fish. Under restricted food, pure populations of GH-transgenic coho salmon decline catastrophically in conditions where pure wild-type groups have only moderate ( 20\%) mortality. The relevance of this finding for climate change and migration is twofold. First, this example shows that pleiotropic effects of loci controlling dispersal-related traits may have other strong fitness effects and therefore limit their suitability for responding to climate change. Second, the low fitness of hungry and aggressive fish under conditions of low food availability, likely to arise for many species in climate-affected and ecologically degraded habitats, can select against highly aggressive, territorial genotypes, thereby allowing proliferation of other genotypes better suited for survival in inhospitable parts of the landscape. Hence, animals surviving and dispersing out of climate-changed habitats could differ-genetically, behaviorally, socially, and physiologically_from the source population.

\section{Temperatures During Comigration Can Limit Its Success}

When mature salmon migrate upstream to breed, both individual and population fitness depend on locomotor ability. Upstream migration can cover hundreds of kilometers and require passage through turbulent and highvelocity sections, challenging both stamina and burst performance. Recent studies of salmon migrating to breeding grounds in British Columbia have shown that increasing 
water temperature is threatening these migrations.

As in other ectotherms, salmon activity metabolism is dependent on environmental temperature, with convex performance curves that reveal species-specific optimal temperatures for swimming (28). An insightful approach with salmon has been to determine the corresponding thermal performance curves for aerobic scope (29): When aerobic scope (AS, calculated as the difference of maximum and resting rate of oxygen consumption) falls to zero, fish can at best stay in place, with no extra energy available to fuel upstream migration. The aerobic scope required to move great distances and cross challenging stretches is not yet known, but the data in hand yield impressive insights. In British Columbia's Fraser River system, distinct populations of salmon enter the rivermouth at different times, migrate to different spawning grounds, and historically have encountered different river temperature regimes. Gates Creek sockeye are early summer migrants that pass farther upstream through warmer water than historically experienced by Weaver Creek sockeye, which enter the river in late summer at cooler temperatures and spawn in a tributary closer to the coast. Chehalis coho are a fall-/winter-migrating salmon that experiences cooler waters. Combining thermal dependency of metabolic rate (28) with temperature data from the river (29) shows that the metabolic performance curves of these three populations correspond closely with the frequency distribution of water temperatures that each population typically encounters during its migration.

In most years, Fraser River populations do not encounter water temperature substantially above $T_{\text {opt }}$ (where maximum AS occurs). The summer of 2004 was an exception, and grimly exemplifies how anomalously high temperature can affect animal locomotion physiology and migration. High water temperature during 2004 was associated with high migration mortality of the Weaver Creek sockeye population. An analysis based on the thermal performance curve of aerobic scope predicted that $30 \%$ of the Weaver population would experience river temperatures that exceeded $T_{\text {crit }}\left(20.4^{\circ} \mathrm{C}\right)$, at which AS is minimal and little or no excess power is available for moving upstream. A simple model based on thermal physiology of metabolism and measures of river water temperature predicted zero lifetime fitness for $30 \%$ of the population [i.e., nearly 38,000 adult salmon in 2004 (29)].

To test this physiological model of salmon migration success, individual fish were released and monitored by positional sensors. Of 83 Weaver Creek salmon, 30\% migrated successfully. Individual success was higher at cooler river temperatures: $0 \%$ when river temperature was $>19.5^{\circ} \mathrm{C}, 27 \%$ at $18.0-19.5^{\circ} \mathrm{C}$, and $78 \%$ for individuals that had entered the river later and migrated at cooler water temperatures. Individuals that spent the most time in the warmest waters had zero success, whereas those that rested in a cold lake had better success.

Because salmon entering the river at different times could have differed in other ways, the authors (29) collected a single group of salmon close to the historic median date for river entry and reared them at different temperatures for 24 days. Mortality during this period was much higher at $10^{\circ} \mathrm{C}(62 \%)$ than at $18^{\circ} \mathrm{C}(32 \%)$. Surviving fish were released into the Fraser River to complete their migration. Of those reared at the cooler temperature, $68 \%$ reached the spawning area, which was comparable to control fish that were freshly captured, tagged, and immediately released at the same river temperature (62\% success). For fish reared at $18^{\circ} \mathrm{C}$, success was only $35 \%$. Thus, warm temperature affects the survival and reproductive success of mature salmon.

The ability to track individual salmon during their long-distance migration in years of different river temperature opens the way for more detailed studies on individual variation. Ideally, one would like to collect noninvasive physiological data and/or tissue samples from individuals when they enter the river, and relate those measures to upstream progression and ultimately success or failure in reaching the breeding area. Studies of this nature have revealed that sockeye salmon that died during
AS: aerobic scope, calculated as the difference of maximum and resting rate of oxygen consumption

$T_{\text {opt }}$ : temperature at which aerobic scope is maximal

$T_{\text {crit }}$ : temperature at which aerobic scope is minimal and little or no excess power is available for movement 
Phenotypic

plasticity: the

expression of multiple

morphs or phenotypes,

often corresponding to

different

environments, by a

given genotype

Trade-off: where an increase in one trait is opposed by a decrease in a second trait

Polymorphic: pertaining to a species or population exhibiting multiple and discontinuous phenotypes upriver migration had higher levels of lactate (30) and osmoregulatory dysfunction (31). A microarray comparison of gene expression in samples of gill tissue obtained from telemetrytagged salmon showed that 88 genes were more highly expressed in surviving fish compared to those that failed to reach the breeding area (32). Identities and functions of these genes have not yet been published, but this study points toward a future in which extensive functional genomics data are combined with telemetry in ways that will greatly enhance the ability to relate physiology to the fate of individual free-living animals.

\section{INSIGHTS FROM FLYING (AND FLIGHTLESS) INSECTS}

\section{Variation in Flight Performance and Behavior, and Its Interactions with Reproduction}

Change in locomotion in response to climatic change is contingent upon standing genetic variation or phenotypic plasticity (33) for locomotion within populations. Genetic variation, plasticity, and genetically variable plasticity in one aspect of locomotion, flight in insects, have been studied extensively in the laboratory and field. These studies address general issues regarding locomotory capacity/evolution and climate change. We first discuss the extent, nature, and underlying causes of locomotor variation in insects, how variants can affect fitness indirectly (through genetic correlations), and how variants provide the raw material for evolutionary change in locomotory ability.

During the past 20-30 years, investigations of genetic variation in locomotor capacity, its phenotypic plasticity, and its covariation with other organismal traits (i.e., functional tradeoffs with reproduction) have used insect flight as a primary model. A first focus of this work has been on flight capability, such as energetic costs of construction and maintenance of the flight apparatus. These studies investigated species exhibiting discontinuous polymorphism for flight, most notably wing polymorphism. A second independent and complementary focus has been on variation in aspects of flight itself (take-off propensity, duration, and distance traveled) in species in which all members can fly. Both foci include the energetic and regulatory basis of positive and negative effects of flight on reproduction (i.e., the extent and mechanisms by which costs of flight capability trade off with reproduction). Such trade-offs, if significant, imply that the very features that prospectively enhance the capacity to comigrate with climatic zones impair the capacity for reproduction thereafter.

Dispersal polymorphism. Dispersal polymorphism consists of one morph (discontinuous phenotype) that can fly (produces fully developed wings; large, functional flight muscles; high concentration of lipid flight fuel; etc.), and one or more morphs that are flightless (underdeveloped wings and flight muscles) within a species (34-40). In many species, there are two categories of flightless morphs: one that never fully develops wings or flight muscles and another that initially can fly but subsequently loses flight ability by histolysis of flight muscles. Totally or partially flightless morphs are common in many major insect groups (e.g., beetles, crickets, grasshoppers, aphids, planthoppers, and true bugs), demonstrating that natural populations vary substantially in flight capability. Indeed, flightlessness likely evolved in insects numerous times (40, 41). The relative frequencies of flightless and flight-capable phenotypes vary extensively within/among even closely related species. In waterstriders, for example, congeneric species can be either entirely flightless or flightcapable. In polymorphic species, the fraction of wingless morphs can vary dramatically (from $0-1$ ) among different populations of the same species or seasonally within a given population (42). In general, flight capability in the field is correlated with gene flow according to population-genetic (allozyme) studies $(43,44)$.

Flight versus reproduction in polymorphic species. Flightlessness is typically associated with substantially increased reproductive effort 
(e.g., increased age-specific fecundity). This finding leads to the central idea that attaining and maintaining flight capability have energetic and fitness costs, even in the absence of flight, and that these costs negatively and often strongly influence reproduction (37-40, 45, 46). The flight-capable morph often is only 20 $30 \%$ as fecund as its flightless congener, and produces eggs more slowly $(37-40,45)$. Importantly, this trade-off is not unique to insect dispersal polymorphism, but it is an extreme example of the general trade-off between locomotion and reproduction in animals [flightoogenesis syndrome $(36,38)]$.

The energetic cost of flight capability is a major driving force for the evolution of flightlessness. The dispensability of flight for feeding or mating in persistent or stable habitats can select for atrophy of the flight apparatus, with the reallocation of energy and substrate savings into egg production $(36,37,39,40,45,47,48)$. Numerous ecological studies, most notably on waterstriders or salt-marsh planthoppers, support this conclusion $(35-37,42)$; flightlessness and habitat persistence are positively related within microhabitats among populations of single species or among species.

Causes of the trade-off between flight capability and reproduction has attracted considerable attention, most notably in the sand cricket, Gryllus firmus (49, 50; see References 39, 51 for reviews). Briefly, a common set of hormones, acting via positive and antagonistic pleiotropic effects, appears simultaneously to regulate aspects of flight muscle and wing growth, and flight itself, in one direction, and aspects of reproduction (yolk protein biosynthesis and uptake into eggs) in the other direction. Thus, hormonal changes that increase egg production impair flight capability. Extensive physiological and biochemical studies have also identified morph-specific alterations in nutrient allocation to the flight apparatus versus ovaries, and alterations in intermediary metabolism of lipids and amino acids that underlie morphspecific production of materials required for flight (triglycerides) versus reproduction (yolk protein) (39, 47, 52). These findings on hormonal integration bear on the evolution of dispersal: Costs and benefits of dispersal on other organismal features (egg production) are consequential in addition to the costs and benefits of dispersal itself.

\section{Flight-Monomorphic Species}

These same costs and benefits have been investigated in numerous species in which all individuals are flight-capable (36, 53-56). The usual foci have been species capable of long-distance migration and, recently, some short-distance fliers [e.g., codling moth (57), Glanville fritillary butterfly (58)]. As in dispersal-polymorphic insects, migratory species exhibit the flightoogenesis syndrome, in which egg production and flight typically occur at different times in adults, with egg production often following dispersal $(36,37,53)$. Thus, long-duration flight appears to compete with reproduction for internal resources, requiring developmental separation of these two processes $(36,54,59)$. Rankin (53) and Rankin \& Burchsted (54) have reviewed endocrine and energetic mechanisms of flight (behavior, duration, etc.) and the flightoogenesis syndrome. Most studies have investigated the influence of juvenile hormone on flight $(53,54,60)$, but not in as much detail as for dispersal-polymorphic species.

In contrast to the above patterns for wingpolymorphic insects, flight sometimes enhances egg production, as in Aphis fabae (61) and longdistance migrants such as Oncopeltus fasciatus and Melanoplus sanguinipes (see References 54 and 36, respectively, for a review). Recent endocrine studies (60) suggest that flight might induce a juvenile hormone peak, which induces egg production once flight terminates.

These studies neither controlled nor investigated food intake following flight but before oviposition. Possibly, therefore, the failure of flight to affect fecundity in these studies resulted from dispersers increasing food consumption following flight. As noted (37, 62, 63), the expression of the trade-off between flight capability and fecundity often is contingent upon or is magnified by reduced nutrient
Flight-oogenesis syndrome: in female insects, where a flight or dispersal phase occurs at a different time than egg production 
input/availability. If "colonizing" species that exhibit long-duration flight must spend more time feeding to compensate for the energetic drain of long-duration flight, then a different trade-off might occur: feeding effort versus reproduction. Costs incurred during increased feeding (e.g., increased predation/parasitism) might explain the reduced longevity of females of the Glanville fritillary butterfly that disperse longer distances (63). In the wing-polymorphic cricket Gryllus texensis, flight per se mitigated some of its own costs by enhancing oviposition and increasing mate attraction (64), although this study also neither controlled nor investigated food intake following flight but before oviposition.

\section{Genetic Variation and Phenotypic Plasticity in Flight Capability, and Their Interaction with Reproduction}

Genetic variation/covariation. Phenotypic variation in flight capability and its covariation with reproductive traits commonly have a strong genetic component in dispersalpolymorphic species. Morph determination can be under either monogenic (holometabolous insects-butterflies, moths, flies, social insects) or polygenic (hemimetabolous speciescrickets, aphids, planthoppers, true bugs) control $(34,35,37,40,45)$. Nearly all detailed genetic work has focused on hemimetabolous insects, notably waterstriders, planthoppers, and especially crickets, and has involved artificial selection, formal sib and half-sib analyses, and other pair-crossing experiments in the laboratory. The most extensive work has investigated the sand cricket, Gryllus firmus (47, 65; see References 35, 66 for a review). Heritabilities are significant (0.3-1.0) for wing polymorphism in various insects $(67,68)$, including 0.65 in $G$. firmus $(45,65)$. In this species, genetic correlations (close to 1.0 in many cases) or correlated responses to selection are strongly positive among wing length, flight muscle mass, lipid (flight fuel) content, and aspects of lipid biosynthesis, and strongly negative between these components of flight capability and ovarian mass (47, 50, 69-71). Thus, the flight-capability versus fecundity trade-off has a genetic basis. Selection on these traits in the laboratory very rapidly yields direct and correlated responses (e.g., 47, 65). For example, changing morph frequencies from 0.5 to 0.9 in either morph direction by standard truncation selection required only five generations (65). Endocrine-genetic studies have identified various hormonal regulators (juvenile hormone and ecdysteroid titers) that covary genetically with flight capability and fecundity, and which are likely important functional causes of the genetic correlations and correlated responses to selection $(49,50,72$, 73; see Reference 51 for a review). Laboratory results thus strongly suggest that (a) insect species can respond strongly to natural selection for increased or decreased flight ability, and $(b)$ this response will be strongly influenced by negative genetic correlations between flight capability and fecundity, which appear to be functionally linked due to coregulation by the same hormones. Both laboratory and field studies show that evolutionary increase in the frequency of the dispersing morph played an important role in the range expansion of several wing-polymorphic cricket species (74).

Phenotypic plasticity and genotype $\mathrm{X}$ environment interaction. Environmental factors such as density, temperature, photoperiod, and food quality/quantity strongly influence the development of flight capability (37, 40, 45, 75-77). Most relevant here are phenotypic plasticity for flight- the capacity for a single genotype to produce different phenotypes in different environments-and genetic variation in this ability. An advantage of phenotypic plasticity over genetic polymorphism is that the same genotype can produce phenotypes (flight-capable versus reproductive/sedentary) to match particular environments (ephemeral versus persistent) (78). Genetic variation for plasticity allows this ability to evolve.

Aphids have been useful in investigating plasticity because their clonal reproduction allows replicated rearing of identical genotypes 
at different environments to identify plasticity and genetic variation for plasticity. Numerous studies have identified plasticity of flight capability. In such plasticity, a single clone can yield different frequencies of winged versus wingless morphs when reared at different photoperiods, temperatures, population densities, or various types of stress, such as on young versus senescing host plants $(76,79-83)$. Many studies of aphid clones have demonstrated genetic variation for phenotypic plasticity [G X E (genotype $\mathrm{X}$ environmental interaction)] for flight capability and correlations with other organismal features $(76,83,84)$. Similarly, phenotypic plasticity and $\mathrm{GX} \mathrm{E}$ for flight capability or performance are evident in various nonaphid species (67, 77, 85-87).

Two noteworthy cases exemplify genetic variation for phenotypic plasticity (G X E). First, variation between phases (genotypes) of the migrant African armyworm, Spodoptera exempta, in long-duration flight is contingent upon larval rearing environment. Phases reared under high larval density differ dramatically in adult flight duration, but not phases reared under low larval density (88). Second, natural populations of planthoppers vary genetically in the ability to produce dispersers in response to population density and habitat permanence (78). Prokelesia dolus and P. marginatus occur sympatrically in persistent, stable habitats, where they each produce a high frequency of the flightless, reproductive morph. In ephemeral habitats, they each produce a higher frequency of the dispersing morph necessary to relocate to new habitats. In a common garden experiment, populations of each species from a persistent habitat produced a lower frequency of the dispersing morph at a given nymphal density than did populations from the more ephemeral habitat. Evolutionary change in the threshold required to produce macropters (dispersers) in response to hopper density appears to result in a higher frequency of the morph that is adaptive for local conditions (e.g., more macropters produced in the ephemeral environment). These examples and the common finding of genetic variation for phenotypic plasticity for dispersal strongly suggest that potential is considerable for evolutionary modification of reaction norms (phenotypic expression across environments) for insect flight.

Laboratory crosses in which progeny were reared under different environmental conditions also suggest that $\mathrm{G} X \mathrm{E}$ for morph induction accounts for seasonality of flight capability in natural populations of many dispersal-polymorphic species. For example, in many bivoltine waterstrider species, the summer population comprises only flightless individuals, whereas the fall population comprises varying proportions of the flightless and flightcapable morphs. G X E observed in the laboratory indicates that long days (i.e., as during summer) typically mask the effects of alleles that encode the dispersing, long-winged phenotype, resulting in exclusively flightless progeny; decreasing day length results in a variable number of dispersers that is cross-dependent $(42,85)$.

\section{Climate Change as an Inducer of Flight Performance}

Increased temperatures and other environmental changes resulting from climate change may actually increase the production of the dispersing morph and thus may promote dispersal. For example, in many wing-polymorphic aphids and planthoppers, host plant deterioration and increased crowding induce the dispersing morph $(37,75,76,82)$. Both inducing situations may become more common if global temperature increases stress on host plants. Increased temperature also induces the dispersing morph in some polymorphic species [crickets (89)], but has the opposite effect in others [aphids (76)]. Indeed, in a few cases, stressful near-intolerable temperatures yielded winged individuals of normally flightless species (G. fultoni; A.J. Zera, unpublished data).

\section{Flightlessness in Semiaquatic Insects: A Case of Extreme Constraint on Flight Ability}

Nearly complete loss of flight capability is common in semiaquatic insects, especially those
G X E: genotype X environment interaction, wherein the influences of genotype and environment on a trait are not additive 
Experimental evolution: study of populations across multiple generations under defined and reproducible conditions, whether in the laboratory or in nature dwelling in streams (42). These insects may thus be unable to escape from climate changeinduced drying of aquatic environments. For example, only one of nine populations (from Virginia to Maine) of the apterous waterstrider, Aquarius remigis, includes winged individuals. In that single population, only $6 \%$ of individuals are winged. Flight-dispersal ability of these winged individuals is likely low $(90,91)$, if it occurs at all, as these individuals often lack flight muscles (92) and show a low propensity to fly (91). Mark-recapture studies have indicated that apterous waterstriders can move overland by walking, but the frequency of movement is low and distances traveled are short, usually $<100$ meters (92; A.J. Zera, unpublished data). Several field studies indicate that reduced dispersal capability constrains the ability of a species to colonize new habits and reduces species persistence. For example, beetles' colonization of new habitats (a reclaimed polder and a new artificial lake in the Netherlands) required seven years and was limited to winged morphs or species (93). The scarcity of the apterus waterstrider, $A$. najas, in the Netherlands is attributed to destruction of suitable aquatic habitats and severely reduced flight capability (work of J.E. Aukema cited in Reference 94).

\section{INSIGHTS FROM SELECTION EXPERIMENTS WITH LOCOMOTION IN RODENTS}

The clear implication of the above is that locomotor or migratory capacity varies phenotypically among and/or within populations of a species, that this variation has a genetic basis, and that the variation is consequential for reproductive fitness. Thus, by implication, locomotor capacity can and should evolve in response to selection for migration. Some of the most direct and convincing evidence that a particular trait can respond to selection, however, comes from experimental evolution approaches (95-98). Here, we review selection experiments that have targeted locomotor behavior or performance in rodents (see also 99, 100). As with flight in insects, focus on a single taxonomic group allows a detailed and nuanced exploration of the relevant mechanism, which nonetheless ought to be broadly generalizable. The conclusion from this review is that both behavioral and physiological aspects of locomotion respond readily to selection in rodents, and that correlated responses to such selection are numerous. Therefore, factors intrinsic to rodents (e.g., genetics, physiology, neurobiology) would seem not to limit their ability to evolve aspects of locomotion in the wild, such as dispersal distances or foraging ranges, should climate change lead to changes in the selection regime that would favor this. The relevant studies are discussed in approximate chronological order.

The first selection experiment to target locomotor behavior per se in rodents involved open-field activity in laboratory mice (Table 1), assessed as photobeam breaks during a 3-min test in a $91 \times 91 \mathrm{~cm}$ arena $(101,102)$. Two sets of five photobeams divided the floor of the arena into 36 squares. Each mouse was tested for three minutes on each of two successive days, and the total number of beams interrupted was the trait on which selection was based. After 30 generations, at which time the high lines still seemed to be responding to selection, individuals from the high-selected lines crossed $\sim 600$ photocell lines in three minutes. Assuming (most liberally) that each trip of a photocell indicates $15 \mathrm{~cm}$ of movement, total movement was $91 \mathrm{~m}$ at an average velocity of $0.51 \mathrm{~m} / \mathrm{s}$ (although movement is actually intermittent). This velocity is virtually identical to that of wild house mice (four to five generations from wild) running in wheels $(103,104)$, about one third of the mean sprint speed of laboratory house mice (104106), and about one half of their maximal aerobic speed (107-111). To our knowledge, the exercise performance abilities of the selected lines of mice are unexamined. In any case, activity in open-field arenas is probably more related to exploration, novelty seeking or anxiety, as opposed to motivation or physiological capacity for exercise (100, 112, 113).

Bunger, Renne, and their colleagues bred laboratory house mice for high or low forced 


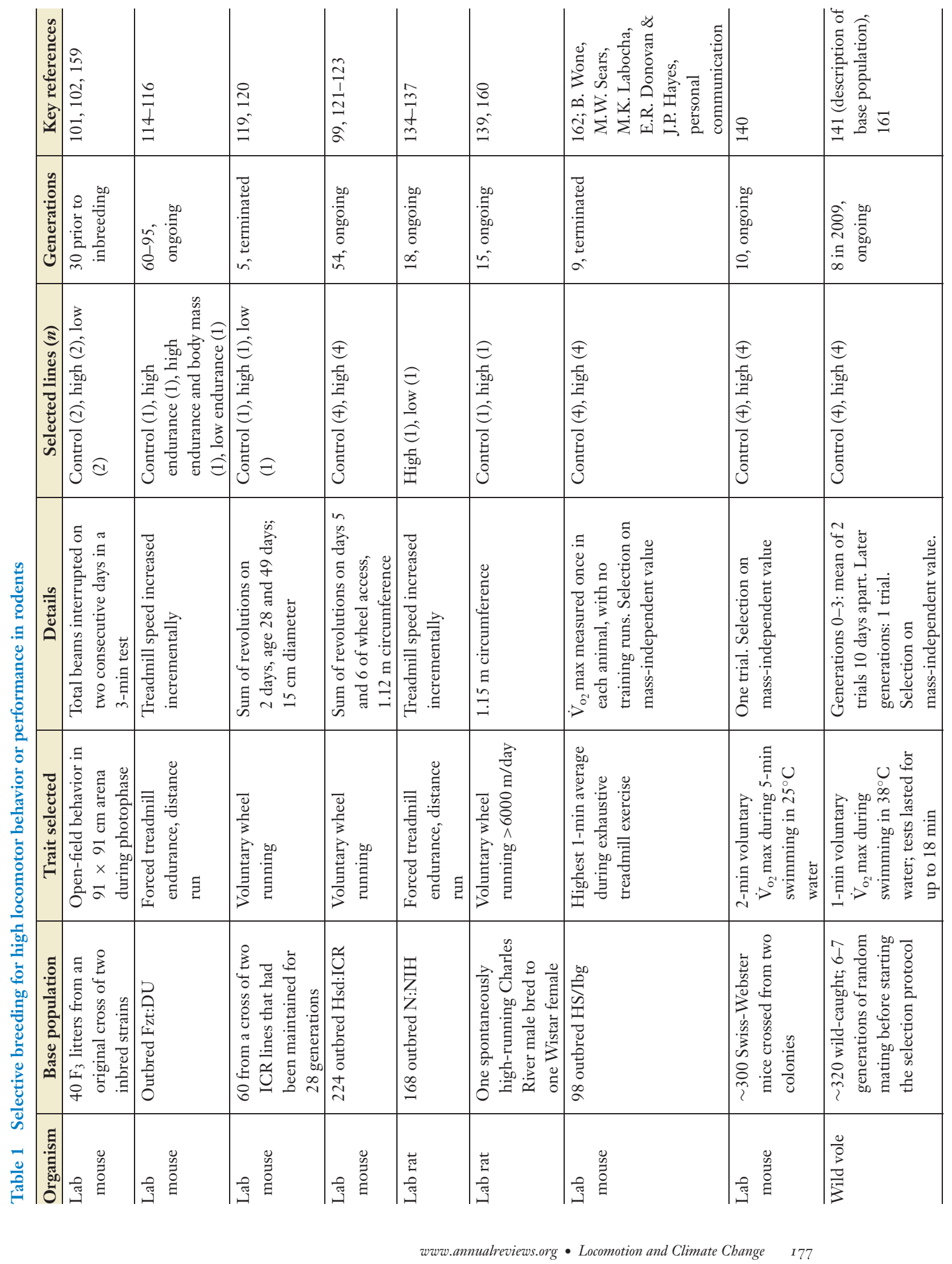


$\dot{V}_{\mathrm{o}_{2}}$ max: maximum rate of oxygen consumption, often an indicator of capacity for sustainable locomotion treadmill performance, with an additional line bred for an index combining high body weight and high treadmill performance $(114,115,116)$. With a few exceptions (e.g., 117), most papers describing these interesting experiments are difficult to obtain (L. Bunger, personal communication; U. Renne, personal communication). These investigators viewed treadmill performance as an index of "stress resistance" (116). Selection for both high and low endurance was successful, and by generation 60 the high line had more than twice the endurance of that of the unselected control line. When tested for open-field behavior and voluntary wheel running, the high-endurance line did not differ statistically from the control line (U. Renne, personal communication). Renne and colleagues also successfully bred mice for high open-field activity during a 3-min test in a round arena, carrying the experiment through 59 generations. By this point openfield activity approximately doubled and treadmill endurance capacity increased by $\sim 10 \%$, as compared with an unselected control line (118).

Dunnington and colleagues bred laboratory house mice for high voluntary wheel running for five generations $(119,120)$. Selection was successful in both directions, and the high line attained daily running distances approximately 1.55 -fold greater than those of the control line.

Garland and colleagues bred four replicate lines of mice for high voluntary wheel running (HR lines), while also maintaining four nonselected control (C) lines $(99,100,121,122)$. Average daily running by the HR lines reached approximately 2.7-fold higher than $\mathrm{C}$ by about generation 16 , and the differential approached threefold after more than 50 generations of selection $(123,124)$. The HR lines have evolved high wheel running in different ways with respect to speed versus duration of activity ("multiple solutions"), and the sexes also differ in how wheel running has increased $(111,124,125)$. HR mice of both sexes exhibit elevated homecage activity (126). As might be expected, HR mice exhibit elevated treadmill endurance capacity (127) and elevated maximal rate of oxygen consumption $\left(\dot{\mathrm{V}}_{\mathrm{O}_{2}} \mathrm{max}\right)$ as measured during forced treadmill exercise $(108,109)$, but not when measured in cold temperatures with a helium-oxygen atmosphere to increase heat loss (107). Several studies have documented that the HR mice exhibit alterations in brain reward centers, including changes in dopamine signaling $(100,121,125,128-130)$. Thus, both exercise abilities and the motivation for (or reward received from) being physically active have been changed by the selection regimen (see also 99, 131). It has been suggested that evolution can "use" alterations in the reward system of the brain to get animals to engage in risky, energetically demanding, or painful activities, and migration behavior could be an example.

One unexpected correlated response in the HR lines has been an increase in predatory aggression, as measured via exposure to live crickets when mice are not fasted (132). Thus, the propensity and ability to run long distances on a daily basis are positively genetically correlated with the tendency to attack, kill, and consume prey. The direction of this genetic correlation would facilitate evolution along the continuum toward an active, predatory life style. In other words, if selection in the wild favored either high locomotor activity, which would likely increase the rate of encounter with prey, or high predatory tendencies, then the other trait would involve in a way that would increase the speed of evolution along this "genetic line of least resistance" (133).

Koch \& Britton (134) bred rats for high or low forced treadmill endurance, but did not maintain a control line. Rapid divergence occurred, and the low capacity runners (LCR) differed from the high-capacity runners (HCR) by 2.7-fold after six generations and 4.5-fold after 11 generations $(134,135)$. Relative to the starting population, most divergence was attributable to increase in the HCR rather than decrease in the LCR. As expected, the lines also diverged in $\dot{\mathrm{V}}_{\mathrm{O}_{2}}$ max measured during forced treadmill exercise (136). A perhaps less 
predictable result is that the HCR mice exhibited $33 \%$ greater voluntary wheel running than the LCR, when females were measured at generation 9-10 (137). Striatal dopaminergic responses to long-term wheel access differed between HCR and LCR rats, suggesting a divergence in the central control of locomotor behaviors (137). HCR rats are smaller than LCR, which is consistent with the reduction in body size observed in HR mice (138).

In 1996, a male rat that spontaneously ran over $6000 \mathrm{~m} /$ day on a wheel appeared in an outbred strain (139). This male was mated with a female from the same strain $\left(\mathrm{F}_{0}\right.$ generation), yielding 6 male and 6 female offspring $\left(\mathrm{F}_{1}\right.$ generation), from which selective sibling mating was started. By generation $\mathrm{F}_{5}$, all individuals of this SPORTS (Spontaneously-RunningTokushima-Shikoku) line were running $>6000 \mathrm{~m} /$ day. As with the Koch/Britton rats and the Garland mice, the SPORTS rats exhibit reduced body mass and alterations in the brain (139).

$\dot{\mathrm{V}}_{\mathrm{O}_{2}}$ max measured during forced exercise on a treadmill sets an upper limit to the intensity of work that aerobic sources of ATP production can sustain. Hence, the $\dot{\mathrm{V}}_{\mathrm{O}_{2}} \max$ is one subordinate phenotype that should coevolve with capacity for sustained endurance exercise. J. P. Hayes and colleagues (personal communication) have successfully bred mice for high $\dot{\mathrm{V}}_{\mathrm{O}_{2}} \max$ for nine generations (Table 1). Both endurance capacity per se and voluntary wheel running ought to be elevated in these lines but have not yet been reported.

Gebczynski \& Konarzewski (140) bred mice for high $\dot{\mathrm{V}}_{\mathrm{O}_{2}} \max$ (highest 2 min) during a 5min swim in $25^{\circ} \mathrm{C}$ water. Because some individuals can float, this measurement of $\dot{\mathrm{V}}_{\mathrm{O} 2} \max$ is not comparable to that obtained by increasing the speed of a treadmill until the animal cannot maintain the pace and/or oxygen consumption plateaus (e.g., 107-109, 136), and should be termed "voluntary $\dot{\mathrm{V}}_{\mathrm{O}_{2}} \max$ " (141). In addition, thermoregulation in $25^{\circ} \mathrm{C}$ water is more challenging than running in air at a similar temperature. Ten generations of selective breeding caused (mass-corrected) voluntary swimming $\dot{\mathrm{V}}_{\mathrm{O}_{2}} \max$ to increase by $12 \%$, as well as treadmill $\dot{\mathrm{V}}_{\mathrm{O}_{2}} \max$ and endurance-running ability, but did not change home-cage activity (140).

Koteja and colleagues have selected wild voles for high mass-corrected $\dot{\mathrm{V}}_{\mathrm{O}_{2}} \max$ (highest $1 \mathrm{~min}$ ) during swimming in $38^{\circ} \mathrm{C}$ water for up to $18 \mathrm{~min}$ (141). After only three generations, the voluntary $\dot{\mathrm{V}}_{\mathrm{O}_{2}}$ max increased by $15 \%$.

The foregoing studies demonstrate the narrow-sense heritability of diverse aspects of locomotor behavior and performance in rodents. They also indicate that both behavior and performance are multifaceted, with varying degrees of correlation between elements of behavior (e.g., open-field versus wheel running), elements of performance capacity (e.g., treadmill endurance versus $\dot{\mathrm{V}}_{\mathrm{O}_{2}} \max$ ), and between the domains of behavior and performance (e.g., voluntary wheel running versus forced treadmill endurance). However, the extent to which animals use their maximal abilities in the wild and the typical strength of selection on locomotor abilities are not well understood $(142,143)$.

As noted above, poleward movement of terrestrial surface isotherms may average several $\mathrm{km}$ per year if current trends continue. Studies of voluntary wheel running (see above; 144) and of movements in the wild indicate that most small mammals can move a few $\mathrm{km}$ in a few days, or even in a single day (145-147). This would imply that the geographic range of such species could easily keep pace with poleward changes in isotherms that are even more extreme than those that currently prevail. To the extent that selection favors increases in migratory behavior and/or locomotor performance abilities, the studies reviewed above also indicate that their rate of evolution should not be a limiting factor. On the other hand, extrinsic factors, such as physical barriers to movement [e.g., large bodies of water, mountains, deserts, roads (148)] or the presence of novel predators or competitors might well limit shifts in geographic ranges. 
Metapopulation: comprises populations of a species distributed among habitat patches

\section{METAPOPULATION DYNAMICS AND VARIATION IN THE DISPERSAL ABILITY OF BUTTERFLIES}

\section{Metapopulation Biology}

Above we have assumed that the comigration with shifting climatic zones involves redistribution from a uniformly less suitable landscape to a uniformly more suitable landscape. In reality, most species, especially in terrestrial environments, have specific habitat requirements that are distributed as patches within the landscape. Metapopulation biology is the study of populations distributed among habitat patches, particularly the way that dispersal and colonization must balance extinction of small, local populations. This work has revealed that dispersal and colonization affect species persistence both in contemporary landscapes (149) and under climate change scenarios (e.g., 150).

The immediate effect of climate change on regional biological communities is likely to be an overall loss of habitat area and fragmentation of remnant habitat patches in the historical range, with concurrent colonization and establishment of new habitat patches in a more poleward range. For example, climate change may cause grassland to replace what was formerly a nearly continuous forest, with an intermediate phase of a network of forest fragments in a matrix of grassland. In such a scenario, the challenge that climate change presents for the species in remnant patches is the extent to which they will be able to colonize more poleward areas before they become extinct from the network of remnant patches in their former range. An insight from metapopulation biology is that we can gain predictive power by examining contemporary fragmented habitats, where dispersal and colonization ability are already key phenotypes that enable the regional persistence of species.

\section{An Example}

A recent study of range expansion in a British butterfly, Hesperia comma, shows how metapopulation biology can be used to address the way species ranges shift. Changes in grazing and climate have created more favorable conditions for this species over recent decades, thereby allowing a range expansion (150). Using a fairly simple metapopulation model parameterized with dispersal and other life-history data from one population network, these authors successfully predicted changes in patch occupancy and range expansion in four other population networks. During the 18 years between surveys, H. comma expanded its range by about $10 \mathrm{~km}$, or $0.56 \mathrm{~km}$ per year. This figure closely matches the overall global average of $0.6 \mathrm{~km}$ per year poleward shift obtained from a wide range of species (20), but is considerably less than the 3.8 to $5.9 \mathrm{~km}$ per year required if current trends of global climate change continue (1). Whether this butterfly's larval host plants or other features, including its dispersal ability, limit its range expansion is unknown.

\section{Integration of Metapopulation \\ Ecology, Physiology, and Functional Genomics}

Further insights into the physiology of patch colonization emerge from an integration of metapopulation ecology, physiology, and functional genomics in another long-term ecological study of a butterfly. Habitat patches of the Glanville fritillary butterfly (Melitaea cinxia) on the Åland archipelago in Finland have been surveyed every year since 1992 (151). These data include the age and connectivity of populations within habitat patches. By collecting larvae or newly emerged adults from old ( $>5$ years continuous occupancy) and new populations, it has been possible to compare the behavior, physiology, and functional genomics of the $\mathrm{F}_{1}$ daughters of successful colonists versus individuals that more closely represent a random draw from the metapopulation. New population females differ in physiology and life history: They emigrate more readily from patches (152), have higher ATP/ADP ratios in their flight muscles after $5 \mathrm{~min}$ of continuous forced flight (153), have higher peak flight metabolic rate, and produce larger clutches of eggs (154). New population females also mate earlier in life, 
deposit eggs earlier in the day, and have reduced life span (63). Under field conditions in a large outdoor population cage, new population females are more mobile (63), and this variation is heritable (58). All of these trait differences are sex-specific, with males showing no population age-dependent differences, presumably because females tend to mate on or near their natal patch prior to dispersal.

To examine more directly the link between physiological traits and dispersal in this species, individual females of known flight metabolic rate were released into a meadow where they were tracked using harmonic radar (155). Butterflies with the highest metabolic rates in laboratory tests tended to move the most after they were released in the field, thereby confirming the link between metabolic performance and dispersal.

These studies in Glanville fritillary butterflies have also revealed that the $F_{1}$ daughters of new population founders are not a random draw of genotypes. Butterflies from new populations show a higher frequency of one allele encoding the glycolytic enzyme phosphoglucose isomerase $[\mathrm{Pgi}(154)]$. In new populations, one clade of Pgi genotypes is more common (distinguished by SNP 111AC), whereas a different clade of Pgi genotypes (SNP 111AA) is more common in old populations (156). Flight metabolic rate of Pgi 111AC females is highest at cooler ambient temperatures, whereas 111AA females perform best at warmer ambient temperatures (155). These temperature dependencies may be responsible for the higher frequency of the AC genotype in new populations, since the high-latitude maritime habitat tends to be fairly cool, with periodic warm sunny summer weather. Cool-preferring Pgi $111 \mathrm{AC}$ genotypes may have more time when they are able to mate, disperse, and oviposit than the more warm-adapted 111AA genotypes. Another butterfly species (Araschnia levana), presently undergoing range expansion in Finland, shows substantially different frequencies of Pgi alleles at the expansion front compared to populations within the ancestral range (V. Mittika \& I. Hanski, unpublished data), which suggests that functional effects of this polymorphism, and more generally changes in dispersal-related genotype frequencies, may indeed be important for range expansion.

This well-established Glanville fritillary ecological system is being developed as a functional genomics model system [i.e., transcriptome sequencing, custom oligonucleotide microarray fabrication, and large-scale SNP discovery (157)]. Microarray studies reveal many significant differences in gene expression between new and old population matrilines reared in a common garden setting (C.W. Wheat, H.W. Fescemyer, J.C. Vera, J. Kvist, M.J. Frilander, I. Hanski \& J. H. Marden, unpublished data), thereby indicating that many more loci than Pgi are likely to be nonrandomly associated with dispersal and colonization.

These results indicate considerable genotypic and phenotypic variation within this fairly small and isolated metapopulation and the beginnings of a mechanistic understanding of how physiological traits interact with colonization/extinction dynamics to maintain genetic variation over time. Because these metapopulation processes are common in fragmented habitats, features like these may apply generally to patchily distributed species. To make the point another way, phenotypes and genotypes that are best at dispersal and colonization are not likely to also be the best at persistence within a patch, and so it may be generally true that patchy habitats and their population dynamics select for and maintain polymorphism in dispersal and other life-history traits. This is relevant for climate change scenarios because range expansion will involve both patch-to-patch movement along the expansion front and an important role for species persistence in areas behind the expanding front.

The existence of considerable standing genetic variation in dispersal and life-history traits in patchily distributed populations contains both good and bad news for the ability of species to colonize more poleward habitat successfully as global climate warms. The good news is that species' response to natural selection for greater mobility, dispersal, and colonization may be 
substantial. Indeed, in the laboratory (see above section on rodents and $35,36,47,67)$ and in nature (74), dispersal capability can evolve rapidly. The bad news is that genotypes selected during range expansion may not be the best for persisting after new habitat has been colonized. It may be that a sufficient number of heterozygotes reach new habitats so that subsequent breeding and within-patch selection for more sedentary traits can rapidly reconstitute the allele frequencies of the parent metapopulations. However, any such prognostication is overly simplistic, since genetic variation within range-shifted populations will be greatly affected by bottlenecks and genetic drift that are likely to occur during ecological disruptions created by climate change.

\section{CONCLUSION}

Extrapolating from a species' capacity for locomotion (as determined by a physiologist) to its ability to escape climatic conditions that will lead to its extinction is simple in concept, but difficult in practice. Regarding any species as uniform with respect to locomotion abilities or behavioral propensities typically belies extensive and highly consequential variation, both phenotypic and genetic, within and among the species' populations. The varying traits themselves, moreover, are highly integrated, such that improvement in locomotion often comes only at the expense of other performance metrics (especially reproduction, energy storage, and local persistence ability). Regarding a species' capacity for locomotion as an independent variable ascertainable with precision typically belies that locomotor capacity is highly plastic, evolvable, and contingent on other traits. As Pelini et al. (158) conclude, "We must move beyond simple assumptions about geographic range change to project future impacts of climate change on biodiversity."

\section{SUMMARY POINTS}

1. Extrapolation from physiological measurements of locomotor capacity and its correlates to capacity for comigration with shifting climate zones should be tempered by an appreciation of (a) microclimatic variation and microhabit selection, $(b)$ the physiological and energetic cost of comigration, and $(c)$ the challenges of establishing a new population once comigration is complete.

2. In addition to capacity to move, comigration requires the timely cueing of locomotor behavior and tolerable conditions during the comigration. As work with salmon exemplifies, each requirement can be unsatisfied during climatic change.

3. Within a species, variation in traits associated with locomotor capacity can be considerable. This variation includes phenotypic plasticity (i.e., many phenotypes from a single genome), genetic variation (primarily single nucleotide polymorphisms, insertion/ deletion polymorphisms, and chromosomal inversions that affect either coding sequence or regulation of expression), and their combination. Varying phenotypes are both continuous and discontinuous (e.g., flying and flightless morphs of insects). Exemplary traits include enzymes of intermediary metabolism, energy stores, metabolic rate, hormones and neurotransmitters, clock genes, locomotor muscle and structure (e.g., wing) size, behavior (e.g., propensity to migrate), locomotor speed and endurance, and thermal sensitivity of locomotion.

4. These traits covary with other traits, and their expression may depend on the environment (e.g., G X E interaction, environmental induction of flight/flightlessness). In some species, variation in locomotor capacity is inversely related to traits associated with behavior, reproduction, and ability to colonize new habitats; that is, locomotor capacity 
trades off against numerous traits essential for persistence of species in the face of climate change.

5. Heritabilities of many relevant traits are such that locomotor capacity can undergo rapid evolution, both experimentally and naturally.

6. Understanding if and how locomotor capacity actually predicts comigratory capacity requires a nuanced, integrative, and comprehensive approach comprising ecology, population and evolutionary biology, genetics and genomics, and developmental biology—in addition to the expected physiology and biochemistry.

\section{FUTURE ISSUES}

1. With the exception of mice, the animal models best suited for an elucidation of locomotor capacity in nature have been exclusive of those to which many of the tools of modern biology are readily applicable. With the rapid pace of technological advancement (e.g., in next-generation sequencing, proteomics, miniaturization of telemeters, etc.), this handicap is certain to abate. As reviewed, several excellent examples of what is to come are already available.

2. The limiting factor in understanding the ramifications of locomotor capacity on vulnerability to environmental change is seldom in the physiology of locomotion, but rather in aspects of biology outside classical physiology and biochemistry. Progress will necessitate broad cross-training and collaboration.

\section{DISCLOSURE STATEMENT}

The authors are not aware of any biases that might be perceived as affecting the objectivity of this review.

\section{ACKNOWLEDGMENTS}

We thank the National Science Foundation for support (grants IOB06-41278 to M.E.F., IOB0543429 to T.G. Jr., EF-0412651 to J.H.M., and IOB-0516973 to A.J.Z.).

\section{LITERATURE CITED}

1. Hansen J, Sato M, Ruedy R, Lo K, Lea DW, Medina-Elizade M. 2006. Global temperature change. Proc. Natl. Acad. Sci. USA 103:14288-93

2. Alerstam T, Hedenstrom A, Akesson S. 2003. Long-distance migration: evolution and determinants. Oikos 103:247-60

3. Costa DP, Sinervo B. 2004. Field physiology: physiological insights from animals in nature. Annu. Rev. Physiol. 66:209-38

4. Wikelski M, Kays RW, Kasdin NJ, Thorup K, Smith JA, Swenson GW. 2007. Going wild: what a global small-animal tracking system could do for experimental biologists. F. Exp. Biol. 210:181-86

5. Weber JM. 2009. The physiology of long-distance migration: extending the limits of endurance metabolism. 7. Exp. Biol. 212:593-97

6. Kearney M, Porter W. 2009. Mechanistic niche modelling: combining physiological and spatial data to predict species' ranges. Ecol. Lett. 12:334-50 
7. Hofmann GE, Todgham A. 2010. Living in the now: physiological mechanisms to tolerate a rapidly changing environment. Annu. Rev. Physiol. 72:127-45

8. Richardson DM, Hellmann JJ, McLachlan JS, Sax DF, Schwartz MW, et al. 2009. Multidimensional evaluation of managed relocation. Proc. Natl. Acad. Sci. USA 106:9721-24

9. Jiguet F, Gadot AS, Julliard R, Newson SE, Couvet D. 2007. Climate envelope, life history traits and the resilience of birds facing global change. Glob. Chang. Biol. 13:1672-84

10. Brooker RW, Travis JMJ, Clark EJ, Dytham C. 2007. Modelling species' range shifts in a changing climate: the impacts of biotic interactions, dispersal distance and the rate of climate change. 7 . Theor. Biol. 245:59-65

11. Pitelka LF, Gardner RH, Ash J, Berry S, Gitay H, et al. 1997. Plant migration and climate change. Am. Sci. 85:464-73

12. Dormann CF. 2007. Promising the future? Global change projections of species distributions. Basic Appl. Biol. 8:387-97

13. Garland T Jr, Carter PA. 1994. Evolutionary physiology. Annu. Rev. Physiol. 56:579-621

14. Feder ME, Bennett AF, Huey RB. 2000. Evolutionary physiology. Annu. Rev. Ecol. Syst. 31:315-41

15. Helmuth B. 2009. From cells to coastlines: How can we use physiology to forecast the impacts of climate change? 7. Exp. Biol. 212:753-60

16. Prinzing A. 2005. Corticolous arthropods under climatic fluctuations: compensation is more important than migration. Ecography 28:17-28

17. Patton S, Crozier GF, Benson AA. 1970. Serum lipids and death of spawning pacific salmon. Nature 225:754-55

18. Piersma T, Lindstrom A. 1997. Rapid reversible changes in organ size as a component of adaptive behavior. Trends Ecol. Evol. 12:134-38

19. Bradshaw WE, Holzapfel CM. 2010. Light, time, and the physiology of biotic response to rapid climate change in animals. Annu. Rev. Physiol. 72:147-66

20. Parmesan C, Yohe G. 2003. A globally coherent fingerprint of climate change impacts across natural systems. Nature 421:37-42

21. Nielsen C, Holdensgaard G, Petersen HC, Bjornsson BT, Madsen SS. 2001. Genetic differences in physiology, growth hormone levels and migratory behavior of Atlantic salmon smolts. F. Fish Biol. 59:2844

22. McCormick SD, Shrimpton JM, Moriyama S, Bjornsson BT. 2002. Effects of an advanced temperature cycle on smolt development and endocrinology indicate that temperature is not a zeitgeber for smolting in Atlantic salmon. 7. Exp. Biol. 205:3553-60

23. Davie A, Minghetti M, Migaud H. 2009. Seasonal variations in clock-gene expression in Atlantic salmon (Salmo salar). Chronobiol. Int. 26:379-95

24. O'Malley KG, Banks MA. 2008. A latitudinal cline in the Chinook salmon (Oncorbynchus tshawytscha) Clock gene: evidence for selection on PolyQ length variants. Proc. Biol. Sci. 275:2813-21

25. Rand DA, Shulgin BV, Salazar D, Millar AJ. 2004. Design principles underlying circadian clocks. f. $R$. Soc. Interface 1:119-30

26. Sundstrom LF, Lohmus M, Johnsson JI, Devlin RH. 2007. Dispersal potential is affected by growth hormone transgenesis in Coho salmon (Oncorbynchus kisutch). Ethology 113:403-10

27. Devlin RH, D'Andrade M, Uh M, Biagi CA. 2004. Population effects of growth hormone transgenic coho salmon depend on food availability and genotype by environment interactions. Proc. Natl. Acad. Sci. USA 101:9303-8

28. Lee CG, Farrell AP, Lotto A, MacNutt MJ, Hinch SG, Healey MC. 2003. The effect of temperature on swimming performance and oxygen consumption in adult sockeye (Oncorbynchus nerka) and coho $(O$. kisutch) salmon stocks. 7. Exp. Biol. 206:3239-51

29. Farrell AP, Hinch SG, Cooke SJ, Patterson DA, Crossin GT, et al. 2008. Pacific salmon in hot water: applying aerobic scope models and biotelemetry to predict the success of spawning migrations. Physiol. Biochem. Zool. 81:697-708

30. Young JL, Hinch SG, Cooke SJ, Crossin GT, Patterson DA, et al. 2006. Physiological and energetic correlates of en route mortality for abnormally early migrating adult sockeye salmon (Oncorbynchus nerka) in the Thompson River, British Columbia. Can. 7. Fish. Aquat. Sci. 63:1067-77 
31. Cooke SJ, Hinch SG, Crossin GT, Patterson DA, English KK, et al. 2006. Mechanistic basis of individual mortality in Pacific salmon during spawning migrations. Ecology 87:1575-86

32. Cooke SJ, Hinch SG, Farrell AP, Patterson DA, Miller-Saunders K, et al. 2008. Developing a mechanistic understanding of fish migrations by linking telemetry with physiology, behavior, genomics and experimental biology: an interdisciplinary case study on adult Fraser River sockeye salmon. Fisheries 33:321-38

33. Phillips K. 2006. Phenotypic plasticity. F. Exp. Biol. 209:i

34. Roff DA, Fairbairn DJ. 1991. Wing dimorphisms and the evolution of migratory polymorphisms among the Insecta. Am. Zool. 31:243-51

35. Roff DA, Fairbairn DJ. 2007. The evolution and genetics of migration in insects. BioScience 57:155-64

36. Dingle H. 1996. Migration: The Biology of Life on the Move. New York: Oxford Univ. Press. vi, 474 pp.

37. Zera AJ, Denno RF. 1997. Physiology and ecology of dispersal polymorphism in insects. Annu. Rev. Entomol. 42:207-30

38. Zera AJ. 2003. The endocrine regulation of wing polymorphism in insects: state of the art, recent surprises, and future directions. Integr. Comp. Biol. 43:607-16

39. Zera AJ. 2009. Wing polymorphism in Gryllus (Orthoptera: Gryllidae): proximate endocrine, energetic and biochemical mechanisms underlying morph specialization for flight vs reproduction. In Phenotypic Plasticity of Insects, ed. DW Whitman, TN Ananthakrishnan, pp. 609-53. Enfield, NH: Science Publ.

40. Harrison RG. 1980. Dispersal polymorphisms in insects. Annu. Rev. Ecol. Syst. 11:95-118

41. Wagner DL, Liebherr JK. 1992. Flightlessness in insects. Trends Ecol. Evol. 7:216-20

42. Vepsalainen K. 1978. Wing dimorphism and diapause in Gerris: determination and adaptive significance. In The Evolution of Insect Migration and Diapause, ed. H Dingle, pp. 218-53. New York: Springer

43. Peterson MA, Denno RF. 1997. The influence of intraspecific variation in dispersal strategies on the genetic structure of planthopper populations. Evolution 51:1189-206

44. Peterson MA, Denno RF. 1998. The influence of dispersal and diet breadth on patterns of genetic isolation by distance in phytophagous insects. Am. Nat. 152:428-46

45. Roff DA. 1986. The evolution of wing dimorphism in insects. Evolution 40:1009-20

46. Denno RF, Olmstead KL, McCloud ES. 1989. Reproductive cost of flight capability — a comparison of life history traits in wing dimorphic planthoppers. Ecol. Entomol. 14:31-44

47. Zera AJ. 2005. Intermediary metabolism and life history trade-offs: lipid metabolism in lines of the wing-polymorphic cricket, Gryllus firmus, selected for flight capability vs early age reproduction. Integr. Comp. Biol. 45:511-24

48. Denno RF, Douglass LW, Jacobs D. 1986. Effects of crowding and host plant nutrition on a wingdimorphic planthopper. Ecology 67:116-23

49. Zera AJ, Tiebel KC. 1989. Differences in juvenile hormone esterase activity between presumptive macropterous and brachypterous Gryllus rubens-implications for the hormonal-control of wing polymorphism. 7. Insect Physiol. 35:7-17

50. Roff DA, Stirling G, Fairbairn DJ. 1997. The evolution of threshold traits: a quantitative genetic analysis of the physiological and life-history correlates of wing dimorphism in the sand cricket. Evolution 51:191019

51. Zera AJ, Harshman LG, Williams TD. 2007. Evolutionary endocrinology: the developing synthesis between endocrinology and evolutionary genetics. Annu. Rev. Ecol. Syst. 38:793-817

52. Zhao ZW, Zera AJ. 2002. Differential lipid biosynthesis underlies a tradeoff between reproduction and flight capability in a wing-polymorphic cricket. Proc. Natl. Acad. Sci. USA 99:16829-34

53. Rankin MA. 1978. Hormonal control of migratory flight. In The Evolution of Insect Migration and Diapause, ed. H Dingle. New York: Springer

54. Rankin MA, Burchsted JCA. 1992. The cost of migration in insects. Annu. Rev. Entomol. 37:533-59

55. Drake VA, Gatehouse AG. 1995. Insect Migration: Tracking Resources through Space and Time. Cambridge/New York: Cambridge Univ. Press. xvii, 478 pp.

56. Kent JW, Rankin MA. 2001. Heritability and physiological correlates of migratory tendency in the grasshopper Melanoplus sanguinipes. Physiol. Entomol. 26:371-80

57. Keil S, Gu HN, Dorn S. 2001. Response of Cydia pomonella to selection on mobility: laboratory evaluation and field verification. Ecol. Entomol. 26:495-501 
58. Saastamoinen M. 2008. Heritability of dispersal rate and other life history traits in the Glanville fritillary butterfly. Heredity 100:39-46

59. Zera AJ, Rankin MA. 1989. Wing dimorphism in Gryllus rubens—genetic basis of morph determination and fertility differences between morphs. Oecologia 80:249-55

60. Min KJ, Jones N, Borst DW, Rankin MA. 2004. Increased juvenile hormone levels after long-duration flight in the grasshopper, Melanoplus sanguinipes. F. Insect Pbysiol. 50:531-7

61. Cockbain AJ. 1961. Viability and fecundity of alate alienicolae of Aphis fabae Scop after flights to exhaustion. F. Exp. Biol. 38:181-87

62. Zera AJ, Harshman LG. 2001. The physiology of life history trade-offs in animals. Annu. Rev. Ecol. Syst. 32:95-126

63. Hanski I, Saastamoinen M, Ovaskainen O. 2006. Dispersal-related life-history trade-offs in a butterfly metapopulation. 7. Anim. Ecol. 75:91-100

64. Guerra PA, Pollack GS. 2009. Flight behavior attenuates the trade-off between flight capability and reproduction in a wing polymorphic cricket. Biol. Lett. 5:229-31

65. Roff DA. 1990. Selection for changes in the incidence of wing dimorphism in Gryllus firmus. Heredity 65:163-68

66. Roff DA. 1996. The evolution of threshold traits in animals. Q. Rev. Biol. 71:3-35

67. Matsumura M. 1996. Genetic analysis of a threshold trait: density-dependent wing dimorphism in Sogatella furcifera (Horvath) (Hemiptera: Delphacidae), the whitebacked planthopper. Heredity 76:229-37

68. Sakashita T, Nakasuji F, Fujisaki K. 1998. Response to selection for different wing forms in the pyrrhocorid bug, Pyrrhocoris sibiricus (Heteroptera: Pyrrhocoridae). Appl. Entomol. Zool. 33:139-41

69. Fairbairn DJ, Roff DA. 1990. Genetic correlations among traits determining migratory tendency in the sand cricket, Gryllus firmus. Evolution 44:1787-95

70. Zera AJ, Larsen A. 2001. The metabolic basis of life history variation: genetic and phenotypic differences in lipid reserves among life history morphs of the wing-polymorphic cricket, Gryllus firmus. F. Insect Physiol. 47:1147-60

71. Zera AJ, Zhao ZW. 2003. Life-history evolution and the microevolution of intermediary metabolism: activities of lipid-metabolizing enzymes in life-history morphs of a wing-dimorphic cricket. Evolution 57:586-96

72. Zera AJ, Huang Y. 1999. Evolutionary endocrinology of juvenile hormone esterase: functional relationship with wing polymorphism in the cricket, Gryllus firmus. Evolution 53:837-47

73. Zera AJ, Bottsford J. 2001. The endocrine-genetic basis of life-history variation: the relationship between the ecdysteroid titer and morph-specific reproduction in the wing-polymorphic cricket Gryllus firmus. Evolution 55:538-49

74. Simmons AD, Thomas CD. 2004. Changes in dispersal during species' range expansions. Am. Nat. 164:378-95

75. Denno RF, Douglass LW, Jacobs D. 1985. Crowding and host plant nutrition-environmental determinants of wing form in Prokelisia marginata. Ecology 66:1588-96

76. Braendle C, Davis GK, Brisson JA, Stern DL. 2006. Wing dimorphism in aphids. Heredity 97:192-99

77. Simpson SJ, Sword GA. 2009. Phase polyphenism in locusts: mechanisms, population consequences, adaptive significance and evolution. In Phenotypic Plasticity of Insects, ed. DW Whitman, TN Ananthakrishnan, p. 894. Enfield, NH: Science Publ.

78. Denno RE, Roderick GK, Peterson MA, Huberty AF, Dobel HG, et al. 1996. Habitat persistence underlies intraspecific variation in the dispersal strategies of planthoppers. Ecol. Monogr. 66:389-408

79. Lees AD. 1961. Clonal polymorphism in aphids. In Insect Polymorphism, ed. JS Kennedy, pp. 68-79. London: R. Entomol. Soc.

80. Groeters FR. 1989. Geographic and clonal variation in the milkweed-oleander aphid, Aphis nerii (Homoptera, Aphididae), for winged morph production, life history, and morphology in relation to host plant permanence. Evol. Ecol. 3:327-41

81. Hardie J, Lees AD. 1985. Endocrine control of polymorphism and polyphenism. In Comprehensive Insect Physiology, Biochemistry and Pharmacology, ed. GA Kerkut, LI Gilbert, pp. 441-90. New York: Pergamon

82. Muller CB, Williams IS, Hardie J. 2001. The role of nutrition, crowding and interspecific interactions in the development of winged aphids. Ecol. Entomol. 26:330-40 
83. Hazell SP, Gwynn DM, Ceccarelli S, Fellowes MDE. 2005. Competition and dispersal in the pea aphid: clonal variation and correlations across traits. Ecol. Entomol. 30:293-98

84. Lamb RJ, Mackay PA. 1979. Variability in migratory tendency within and among natural populations of the pea aphid, Acyrthosiphon pisum. Oecologia 39:289-99

85. Zera AJ, Innes DJ, Saks ME. 1983. Genetic and environmental determinants of wing polymorphism in the waterstrider Limnoporus canaliculatus. Evolution 37:513-22

86. Zera AJ, Tiebel KC. 1988. Brachypterizing effect of group rearing, juvenile hormone iii and methoprene in the wing dimorphic cricket, Gryllus rubens. 7. Insect Physiol. 34:489-98

87. Roff DA, Gelinas MB. 2003. Phenotypic plasticity and the evolution of trade-offs: the quantitative genetics of resource allocation in the wing dimorphic cricket, Gryllus firmus. F. Evol. Biol. 16:55-63

88. Woodrow KP, Gatehouse AG, Davies DA. 1987. The effect of larval phase on flight performance of African armyworm moths, Spodoptera exempta (Walker) (Lepidoptera, Noctuidae). Bull. Entomol. Res. 77:113-22

89. McFarlane JE. 1962. Effect of diet and temperature on wing development in Gryllodes sigillatrus (Walk.) (Orthoptera: Gryllidae). Ann. Soc. Entomol. Quebec 7:28-33

90. Zera AJ. 1981. Genetic structure of 2 species of waterstriders (Gerridae, Hemiptera) with differing degrees of winglessness. Evolution 35:218-25

91. Fairbairn D, Desranleau L. 1987. Flight threshold, wing muscle histolysis, and alary polymorphismcorrelated traits for dispersal tendency in the Gerridae. Ecol. Entomol. 12:13-24

92. Fairbairn DJ. 1986. Does alary dimorphism imply dispersal dimorphism in the waterstrider, Gerris remigis? Ecol. Entomol. 11:355-68

93. denBoer PJD. 1970. On significance of dispersal power for populations of carabid beetles (Coleoptera, Carabidae). Oecologia 4:331-43

94. Petrakis RV, Legakis A. 2005. Insect migration and dispersal with emphasis on Mediterranean ecosystems. In Migration of Organisms. Climate, Geography, Ecology, ed. AMT Elewa, pp. 86-126. Heidelberg: Springer

95. Swallow JG, Garland T Jr. 2005. Selection experiments as a tool in evolutionary and comparative physiology: insights into complex traits-an introduction to the symposium. Integr. Comp. Biol. 45:387-90

96. Chippindale AK. 2006. Experimental evolution. In Evolutionary Genetics: Concepts and Case Studies, ed. C Fox, J Wolf, pp. 482-501. Oxford: Oxford Univ. Press

97. Bell G. 2008. Selection: the Mechanism of Evolution. Oxford/New York: Oxford Univ. Press. xiii, 553 pp.

98. Garland T Jr, Rose MR, eds. 2009. Experimental Evolution: Concepts, Methods, and Applications of Selection Experiments. Berkeley: Univ. Calif. Press. In press. 730 pp.

99. Swallow JG, Hayes JP, Koteja P, Garland T Jr. 2009. Selection experiments and experimental evolution of performance and physiology. See Ref. 98, pp. 301-51

100. Rhodes JS, Kawecki TJ. 2009. Behavior and neurobiology. See Ref. 98, pp. 263-300

101. Defries JC, Gervais MC, Thomas EA. 1978. Response to 30 generations of selection for open-field activity in laboratory mice. Behav. Genet. 8:3-13

102. Defries JC, Wilson JR, McClearn GE. 1970. Open-field behavior in mice-selection response and situational generality. Behav. Genet. 1:195-211

103. Perrigo G. 1987. Breeding and feeding strategies in deer mice and house mice when females are challenged to work for their food. Anim. Behav. 35:1298-316

104. Dohm MR, Richardson CS, Garland TJr. 1994. Exercise physiology of wild and random-bred laboratory house mice and their reciprocal hybrids. Am. F. Physiol. Regul. Integr. Comp. Physiol. 267:R1098-108

105. Dohm MR, Hayes JP, Garland T Jr. 1996. Quantitative genetics of sprint running speed and swimming endurance in laboratory house mice (Mus domesticus). Evolution 50:1688-701

106. Friedman WA, Garland T Jr, Dohm MR. 1992. Individual variation in locomotor behavior and maximal oxygen-consumption in mice. Physiol. Behav. 52:97-104

107. Rezende EL, Chappell MA, Gomes FR, Malisch JL, Garland T Jr. 2005. Maximal metabolic rates during voluntary exercise, forced exercise, and cold exposure in house mice selectively bred for high wheel-running. F. Exp. Biol. 208:2447-58

108. Rezende EL, Garland TJr, Chappell MA, Malisch JL, Gomes FR. 2006. Maximum aerobic performance in lines of Mus selected for high wheel-running activity: effects of selection, oxygen availability and the mini-muscle phenotype. 7. Exp. Biol. 209:115-27 
109. Swallow JG, Garland T Jr, Carter PA, Zhan WZ, Sieck GC. 1998. Effects of voluntary activity and genetic selection on aerobic capacity in house mice (Mus domesticus). 7. Appl. Physiol. 84:69-76

110. Girard I, McAleer MW, Rhodes JS, Garland T Jr. 2001. Selection for high voluntary wheel-running increases speed and intermittency in house mice (Mus domesticus). F. Exp. Biol. 204:4311-20

111. Rezende EL, Gomes FR, Chappell MA, Garland T Jr. 2009. Running behavior and its energy cost in mice selectively bred for high voluntary locomotor activity. Physiol. Biochem. Zool. 82:662-79

112. Kliethermes CL, Crabbe JC. 2006. Genetic independence of mouse measures of some aspects of novelty seeking. Proc. Natl. Acad. Sci. USA 103:5018-23

113. Dishman RK, Armstrong RB, Delp MD, Graham RE, Dunn AL. 1988. Open-field behavior is not related to treadmill performance in exercising rats. Physiol. Behav. 43:541-46

114. Dietl G, Langhammer M, Renne U. 2004. Model simulations for genetic random drift in the outbred strain Fzt: DU. Arch. Tierz. 47:595-604

115. Rehfeldt C, Walther K, Albrecht E, Nurnberg G, Renne U, Bunger L. 2002. Intrinsic properties of muscle satellite cells are changed in response to long-term selection of mice for different growth traits. Cell Tissue Res. 310:339-48

116. Bunger L, Renne U, Dietl G. 1994. 60 generations selection for an index combining high body weight and high stress resistance in laboratory mice. World Congr. Genet. Appl. Livest. Prod. 19:16-19

117. Falkenberg H, Langhammer M, Renne U. 2000. Comparison of biochemical blood traits after long-term selection on high or low locomotory activity in mice. Arch. Tierz. 43:513-22

118. Renne U, Langhammer M, Kuhla S. 1997. Selection response after long-term selection for behavior in mice. Proc. Abstr. Annu. Meet. Eur. Assoc. Anim. Prod., 48th, Vienna, Aust., G3.23, p. 39

119. Dunnington EA, White JM, Vinson WE. 1981. Selection for serum-cholesterol, voluntary physicalactivity, 56-day body-weight and feed-intake in random-bred mice. 1. Direct responses. Can. 7. Genet. Cytol. 23:533-44

120. Dunnington EA, White JM, Vinson WE. 1981. Selection for serum-cholesterol, voluntary physicalactivity, 56-day body-weight and feed-intake in random-bred mice. 2. Correlated responses. Can. 7 . Genet. Cytol. 23:545-55

121. Rhodes JS, Gammie SC, Garland T Jr. 2005. Neurobiology of mice selected for high voluntary wheelrunning activity. Integr. Comp. Biol. 45:438-55

122. Swallow JG, Carter PA, Garland T Jr. 1998. Artificial selection for increased wheel-running behavior in house mice. Behav. Genet. 28:227-37

123. Garland TJr. 2003. Selection experiments: an underutilized tool in biomechanics and organismal biology. In Vertebrate Biomechanics and Evolution, ed. VL Bels, JP Gasc, A Casinos, pp. 23-56. Oxford, UK: BIOS Sci.

124. Garland T Jr, Kelly SA, Malisch JL, Kolb EM, Hannon RM, et al. 2009. How to run far: multiple solutions and sex-specific responses to selective breeding for high voluntary activity levels. Proc. R. Soc. London Ser. B. In review

125. Keeney BK, Raichlen DA, Meek TH, Wijeratne RS, Middleton KM, et al. 2008. Differential response to a selective cannabinoid receptor antagonist (SR141716: rimonabant) in female mice from lines selectively bred for high voluntary wheel-running behavior. Behav. Pharmacol. 19:812-20

126. Malisch JL, Breuner CW, Kolb EM, Wada H, Hannon RM, et al. 2009. Behavioral despair and homecage activity in mice with chronically elevated baseline corticosterone concentrations. Behav. Genet. 39:192-201

127. Meek TH, Lonquich BP, Hannon RM, Garland T Jr. 2009. Endurance capacity of mice selectively bred for high voluntary wheel running. F. Exp. Biol. 212:2908-17

128. Belke TW, Garland T Jr. 2007. A brief opportunity to run does not function as a reinforcer for mice selected for high daily wheel-running rates. 7. Exp. Anal. Behav. 88:199-213

129. Pringle RB. 2005. Exercise, ethology, and monoaminergic activity in mice selected for increased voluntary wheelrunning. M.Sc. thesis. Univ. S. Dakota. iv, 56 pp.

130. Bronikowski AM, Rhodes JS, Garland T Jr, Prolla TA, Awad TA, Gammie SC. 2004. The evolution of gene expression in mouse hippocampus in response to selective breeding for increased locomotor activity. Evolution 58:2079-86 
131. Gomes FR, Rezende EL, Malisch JL, Lee SK, Rivas DA, et al. 2009. Glycogen storage and muscle glucose transporters (GLUT-4) of mice selectively bred for high voluntary wheel running. F. Exp. Biol. 212:238-48

132. Gammie SC, Hasen NS, Rhodes JS, Girard I, Garland T Jr. 2003. Predatory aggression, but not maternal or intermale aggression, is associated with high voluntary wheel-running behavior in mice. Horm. Behav. 44:209-21

133. Schluter D. 1996. Adaptive radiation along genetic lines of least resistance. Evolution 50:1766-74

134. Koch LG, Britton SL. 2001. Artificial selection for intrinsic aerobic endurance running capacity in rats. Physiol. Genomics 5:45-52

135. Wisloff U, Najjar SM, Ellingsen O, Haram PM, Swoap S, et al. 2005. Cardiovascular risk factors emerge after artificial selection for low aerobic capacity. Science 307:418-20

136. Gonzalez NC, Kirkton SD, Howlett RA, Britton SL, Koch LG, et al. 2006. Continued divergence in $\mathrm{Vo}_{2 \max }$ of rats artificially selected for running endurance is mediated by greater convective blood $\mathrm{O}_{2}$ delivery. 7. Appl. Physiol. 101:1288-96

137. Waters RP, Renner KJ, Pringle RB, Summers CH, Britton SL, et al. 2008. Selection for aerobic capacity affects corticosterone, monoamines and wheel-running activity. Physiol. Behav. 93:1044-54

138. Swallow JG, Koteja P, Carter PA, Garland T Jr. 1999. Artificial selection for increased wheel-running activity in house mice results in decreased body mass at maturity. F. Exp. Biol. 202:2513-20

139. Morishima M, Harada N, Hara S, Sano A, Seno H, et al. 2006. Monoamine oxidase A activity and norepinephrine level in hippocampus determine hyperwheel running in SPORTS rats. Neuropsychopharmacology 31:2627-38

140. Gebczynski AK, Konarzewski M. 2009. Metabolic correlates of selection on maximum aerobic capacity in laboratory mice: a test of the model of the evolution of endothermy. F. Exp. Biol. 212:2872-78

141. Sadowska ET, Labocha MK, Baliga K, Stanisz A, Wroblewska AK, et al. 2005. Genetic correlations between basal and maximum metabolic rates in a wild rodent: consequences for evolution of endothermy. Evolution 59:672-81

142. Irschick DJ, Garland T Jr. 2001. Integrating function and ecology in studies of adaptation: Investigations of locomotor capacity as a model system. Annu. Rev. Ecol. Syst. 32:367-96

143. Irschick DJ, Meyers JJ, Husak JF, Le Galliard JF. 2008. How does selection operate on whole-organism functional performance capacities? A review and synthesis. Evol. Ecol. Res. 10:177-96

144. Dewsbury DA. 1980. Wheel-running behavior in 12 species of muroid rodents. Behav. Process. 5:271-80

145. Carbone C, Cowlishaw G, Isaac NJB, Rowcliffe JM. 2005. How far do animals go? Determinants of day range in mammals. Am. Nat. 165:290-97

146. Goszczynski J. 1986. Locomotor activity of terrestrial predators and its consequences. Acta Theriol. 31:79-95

147. Garland T Jr. 1983. Scaling the ecological cost of transport to body-mass in terrestrial mammals. Am. Nat. 121:571-87

148. Garland T Jr, Bradley WG. 1984. Effects of a highway on Mojave Desert rodent populations. Am. Midl. Nat. 111:47-56

149. Hanski I, Ovaskainen O. 2000. The metapopulation capacity of a fragmented landscape. Nature 404:75558

150. Wilson RJ, Davies ZG, Thomas CD. 2009. Modelling the effect of habitat fragmentation on range expansion in a butterfly. Proc. Biol. Sci. 276:1421-27

151. Hanski I. 1999. Habitat connectivity, habitat continuity, and metapopulations in dynamic landscapes. Oikos 87:209-19

152. Hanski I, Breuker CJ, Schöps K, Setchfield R, Nieminen M. 2002. Population history and life history influence the migration rate of female Glanville fritillary butterflies. Oikos 98:87-97

153. Hanski I, Erälahti C, Kankare M, Ovaskainen O, Sirén H. 2004. Variation in migration propensity among individuals maintained by landscape structure. Ecol. Lett. 7:958-66

154. Haag CR, Saastamoinen M, Marden JH, Hanski I. 2005. A candidate locus for variation in dispersal rate in a butterfly metapopulation. Proc. Biol. Sci. 272:2449-56

155. Niitepõld K, Smith AD, Osborne JL, Reynolds DR, Carreck NL, et al. 2009. Flight metabolic rate and Pgi genotype influence butterfly dispersal rate in the field. Ecology 190:2223-32 
156. Orsini L, Wheat CW, Haag CR, Kvist J, Frilander MJ, Hanski I. 2009. Fitness differences associated with Pgi SNP genotypes in the Glanville fritillary butterfly (Melitaea cinxia). F. Evol. Biol. 22:367-75

157. Vera JC, Wheat CW, Fescemyer HW, Frilander MJ, Crawford DL, et al. 2008. Rapid transcriptome characterization for a nonmodel organism using 454 pyrosequencing. Mol. Ecol. 17:1636-47

158. Pelini SL, Dzurisin JDK, Prior KM, Williams CM, Marsicos TD, et al. 2009. Translocation experiments with butterflies reveal limits to enhancement of poleward populations under climate change. Proc. Natl. Acad. Sci. USA 106:11160-65

159. Flint J, DeFries JC, Henderson ND. 2004. Little epistasis for anxiety-related measures in the DeFries strains of laboratory mice. Mamm. Genome 15:77-82

160. Morishima-Yamato M, Hisaoka F, Shinomiya S, Harada N, Matoba H, et al. 2005. Cloning and establishment of a line of rats for high levels of voluntary wheel running. Life Sci. 77:551-61

161. Sadowska ET, Baliga-Klimczyk K, Chrzascik KM, Koteja P. 2008. Laboratory model of adaptive radiation: a selection experiment in the bank vole. Physiol. Biochem. Zool. 81:627-40

162. Wone B, Sears MW, Labocha MK, Donovan ER, Hayes JP. 2009. Genetic variances and covariances of aerobic metabolic rates in laboratory mice. Proc. R. Soc. B 276:3695-704 